\title{
The role of training in evacuation
}

\author{
F. Russo, C. Rindone \& M. R. Trecozzi \\ DIMET, Dipartimento di Informatica, Matematica, Elettronica e \\ Trasporti, Università degli Studi Mediterranea di Reggio Calabria, Italy
}

\begin{abstract}
Evacuation planning is finalized to reduce exposure risk; it comprises a set of different activities. In this paper a focus on non-material training activities is presented. These activities improve capability in evacuation planning and implementation. A classification training activities is proposed. In particular European Union (EU) and United States of America (USA) training approaches are analyzed.

Keywords: evacuation planning, training, discussion-based.
\end{abstract}

\section{Introduction}

Risk can be defined as a cardinal measure of potential economic loss, human injury or environmental damage in terms of both incident probability and the magnitude of the loss, injury or damage. Risk (R) can be expressed by multiplying three elements: occurrence of an event $(\mathrm{P})$, in terms of probability or frequency of a specific event actually happening; vulnerability (V), related to the resistance of the infrastructures when the event occurs; exposure $(\mathrm{N})$, related to the equivalent homogeneous weighted value of people, goods and infrastructures affected during and after the event [1]. Equation of risk, in the classical way, can be written in the form:

$$
\mathrm{R}=\mathrm{P} \mathrm{V} \mathrm{N}
$$

Below we consider the exposure component. The main macro-activity to reduce exposure is evacuation, which consists in reducing the number of users and goods that can experience negative effects when emergency events occur [1].

These exposure activities are a subset of emergency planning activities that are, at international level, defined how (Australia [2], USA [4], and EU [5]): mitigation, comprising activities carried out in advance of an emergency event 
(e.g. land management and planning; public information campaigns); preparedness, comprising activities to ensure, if an emergency occurs, that communities, resources and services are capable of responding to the effects (e.g. evacuation planning; exercising, training and testing of emergency service staff); response, including activities to control, limit or modify the emergency and to reduce its consequences (e.g. implementation of emergency plans and procedures in response to emergency incidents and provision); recovery (community), including activities to support reconstruction of physical infrastructure after emergency situations (e.g. restoration of essential services, temporary housing; long-term medical care).

Exposure activities for each disastrous event can be classified respect to time slice, that is the period over which a generic event evolves. Time slice varies according to the scenario: several years for long term, some months or days for short term, some days or hours or minutes for now-casting. Within the macro time slice $\Delta$, four main intervals have to be defined $\left(\Delta_{0}, \Delta_{1}, \Delta_{2}, \Delta_{3}\right)[6]$ :

- $\Delta_{0}=\left(\mathrm{t}_{0}, \mathrm{t}_{1}\right]$ between the times

$t_{0}$, the time when the study of the evacuation plan is started;

$t_{1}$, the time when the hazardous event is known to happen or supposed forecasted;

in this interval mitigation and preparedness activities can be implemented;

- $\Delta_{1}=\left(\mathrm{t}_{1}, \mathrm{t}_{2}\right]$ between the times $\mathrm{t}_{2}$ and $\mathrm{t}_{3}$, the time when the threat occurs and becomes a dangerous event and starts its effects;

in this interval response activities can be implemented;

- $\quad \Delta_{2}=\left(\mathrm{t}_{2}, \mathrm{t}_{3}\right]$ between times $\mathrm{t}_{2}$ and $\mathrm{t}_{3}$, the time when the final effect occurs and people cannot be rescued;

in this interval response activities can be implemented;

- $\Delta_{3}=\left(t_{3}, t_{4}\right]$ between times $t_{3}$ and $t_{4}$, the time when the hazardous event ceases its effect on the population;

in this interval recovery activities can be implemented.

Evacuation plan is developed within time slice but before time $\mathrm{t}_{1}$ (interval $\Delta 0$ ). Risk assessment consists in evaluating the possible threats and their relative evolution in the possible intervals $\Delta_{1}, \Delta_{2}$ and $\Delta_{3}$. In general the interval $\Delta_{0}$ is greater than the other intervals; for some threats some of the intervals $\Delta_{1}, \Delta_{2}$ and $\Delta_{3}$ are with zero extension. For example, if we have to evaluate the risk for seismic threats, the interval $\Delta_{0}$ is evaluated in the order of 100 years. The dimension of the intervals $\Delta_{1}$ is zero, and $\Delta_{2}$ and $\Delta_{3}$ are not-zero. The size of the intervals $\Delta_{1}$ is about one hour, depending on the distance of the source.

Events can be classified as [6]:

- delayed approach, when $\Delta_{1}+\Delta_{2} \neq 0$ and all the people (or some of) can be evacuated;

- immediate approach, when $\Delta_{1}+\Delta_{2} \rightarrow 0$, and not all the people can be evacuated. 


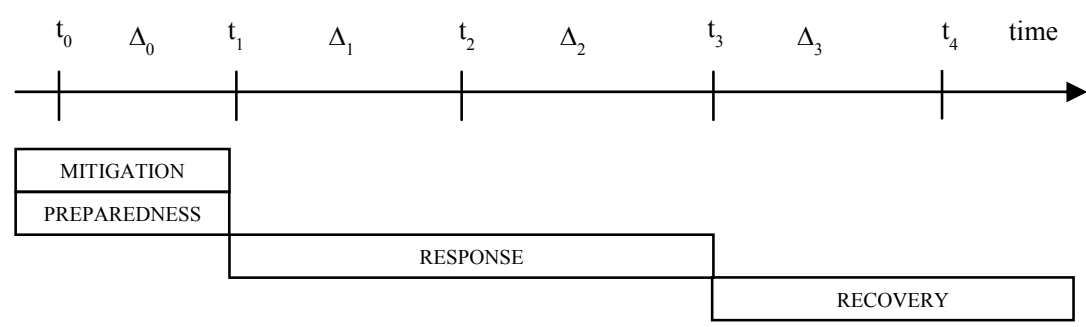

Figure 1: Reduction exposure activities.

For disastrous events with delayed approach evacuation planning can be implemented. Activities for evacuation planning can be classified into homogeneous classes in terms of execution time and the decision-maker of single activities: activities related to material infrastructures that include interventions to modify the physical characteristics of transport system elements (linear; surface); non-material activities that comprise consolidated research, learning and training, and others concerning telematics or Intelligent Transportation Systems; activities related to equipment which include interventions to provide operative tools that contribute to set up specific services in evacuation conditions; management activities comprising interventions to manage the transportation system; this class includes traffic regulations; governance and institutional activities, including interventions to regulate the transportation system.

In this paper non material activities are focused [7]. They are activities to increase stakeholders' knowledge in terms of research, learning and training; for instance, such improvements can contribute to modifying user behaviour in travel choices during an evacuation. In this class can be also possible to consider an extension of classical definition of non material activities including the activities to improve the technological characteristics of transport system elements, adopting Intelligent Transportation Systems (ITS); for instance, ITS contribute to promoting the exchange of information among stakeholders involved and supporting transport system management in emergency conditions.

In the following we analyze research, learning and training activities starting from experiences at international level. These activities contribute to improve capability of subjects involved in evacuation planning. For instance USA Department of Homeland Security (DHS) defines capability how a characteristic derived from a combination of properly planned, organized, equipped, trained, and exercised personnel who achieve the intended outcome.

In section 2 a training activities classification is presented. Two principal classes of training activities are introduced: discussion - based and operation based. In this paper discussion based activities are focused. To verify the proposed framework, in the specific discussion based class, two different approaches are analysed: in sections $3.1 \mathrm{EU}$ approach; in section 3.2 USA approach. Some final considerations are reported in section 3.3. 


\section{Training activities classification}

A possible classification includes the following two macro classes (Figure 2):

- Discussion - based activities, to discuss between trainer and participants about current plans, policies, agreements, and evacuation procedures;

- Operation - based activities, to simulate, in an operational context, a real emergency situation and to implement plans, policies, agreements, and evacuation procedures.

- Discussion - based activities includes two classes:

without interaction between trainers and participants; trainers provide information about activities to implement in evacuation conditions; they are, for instance,

- seminars to provide at participants an overview of authorities, strategies, plans, policies, procedures, protocols, response resources, and/or concepts and ideas about evacuations;

- workshops to create or generate plans, analysis, or design to support organizational efforts;

- with interaction between trainers and participants; following trainer indications, participants realise, for instance, practical exercises on activities to implement in evacuation conditions; they are, for istance tabletops, games and models; in particular a set of models to simulate a transportation system in evacuation conditions [7-10] or a set of models for paths design of emergency vehicles $[11,12]$ are incluted in a training courses.

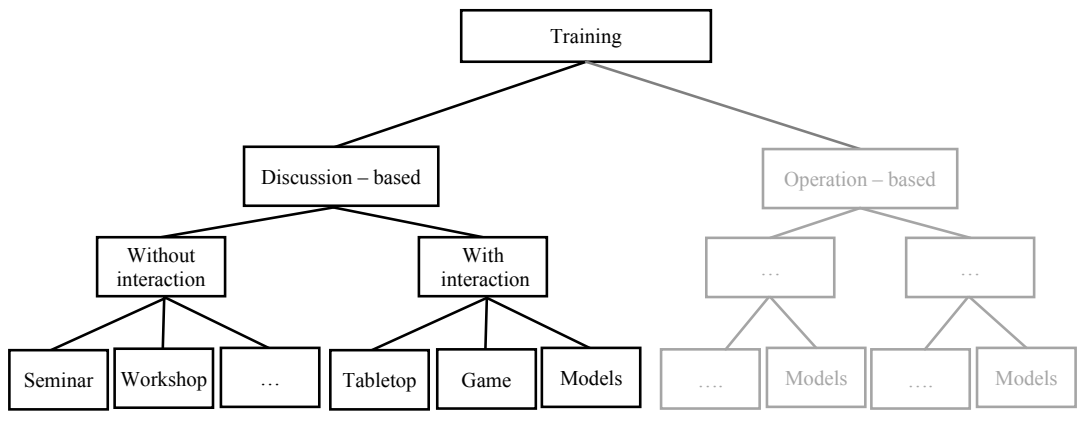

Figure 2: Classification scheme of training activities.

It must be noted that, in general, the organized courses in the training context, considers a mix of different discussion - based activities and each of these activities, contributes to increase capability at different levels. For instance, training activities contribute to increase designing capability of some transportation system components in evacuation conditions [13-18]. 


\section{International experiences}

In the set of international experiences in training we selected the EU (section 3.1) and USA (section 3.2) study cases.

\subsection{The EU experience}

The European Civil Protection (ECP), by means of the Community Mechanism for Civil Protection (CMCP), has organized a Monitoring and Information Centre (MIC); a Common Emergency and Information System (CESIS); a Training program [18]. Figure 3 shows EU education and training activities. The Training program has been set up with a view to improving the co-ordination of civil protection assistance interventions by ensuring compatibility and complementary between the intervention teams from the participating states. The program comprises:

- training courses, that corresponds to discussion - based before recalled;

- $\quad$ simulation exercises, that corresponds to operation - based;

- $\quad$ exchange of expert.
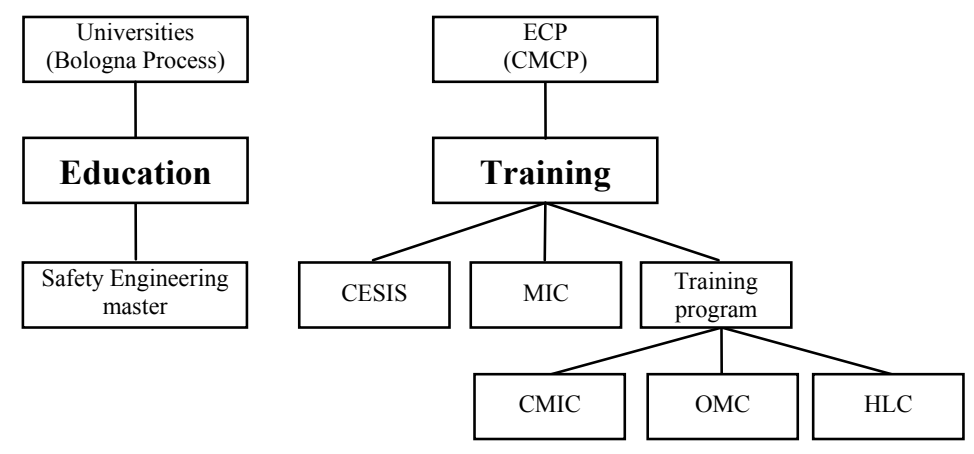

Figure 3: $\quad$ EU education and training scheme.

The CMCP program describes the training program which is specified 12 courses. All courses combine theory and field experience, as well as international guidelines and standard operating procedures. The program is organized on three skill levels (Figure 4):

- Community Mechanism Induction Course (CMIC) introduces participants to the Community Mechanism and provide them with the basic knowledge and skills to prepare themselves for international civil protection missions (Introduction);

- Operational Management Course (OMC) focuses on coordination and course topics include internationally agreed guidelines and procedures, planning, information management and how key partners work on an operational level, as well as ethics and code of conduct (Operational); 
- High Level Coordination (HLC) focuses on emergencies outside the Community Mechanism's geographical area and how to work within a wider international framework (Management).

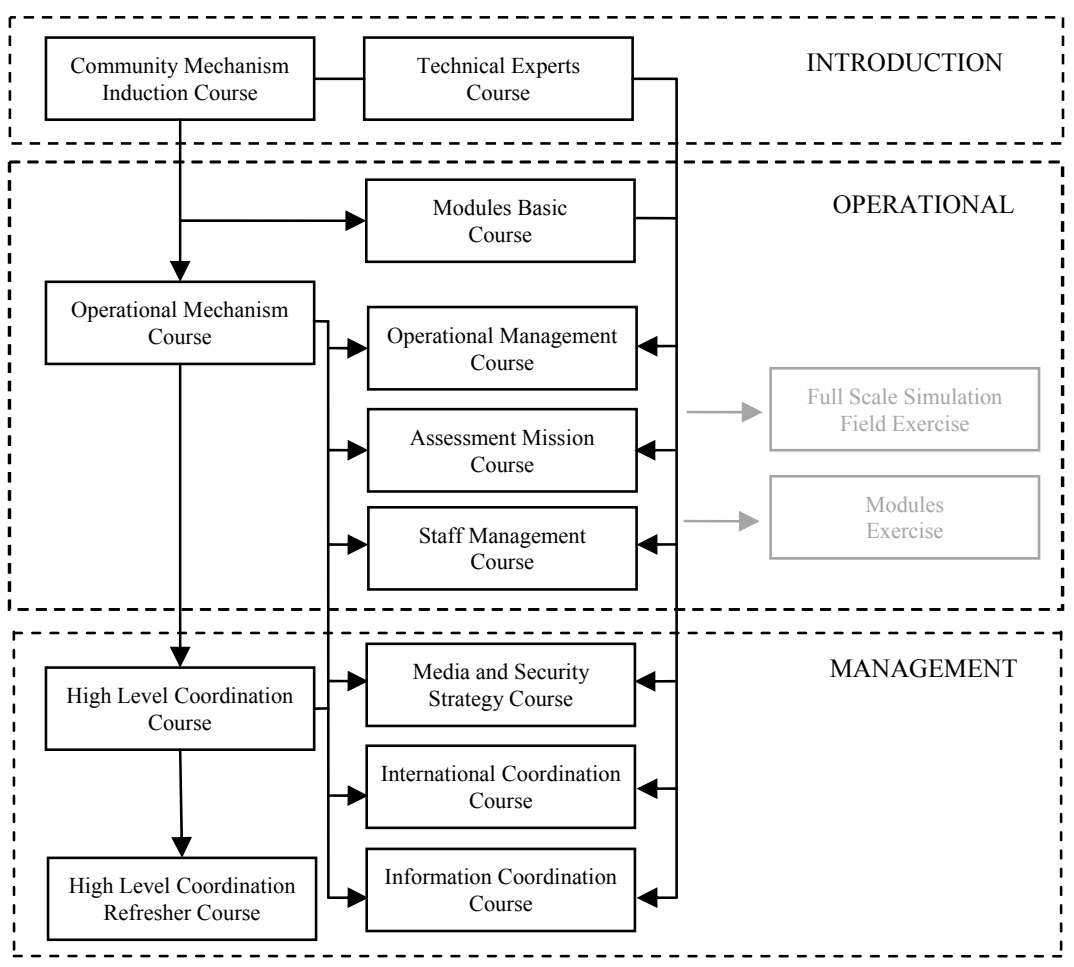

Figure 4: $\quad$ EU experience [5].

After discussion - based activities, the CMCP program includes different types of exercises (full scale simulations and modules).

Higher education activities in EU are regulated by Bologna Process that aims to realize a European Higher Education Area [19].

Member States that participating in this program established a standard for higher education activities. For instance in Italy the Ministry of Research have instituted safety engineering bachelor programs and master programs, for instance Safety Engineering master [20].

In Italy emergency training activities are regulated by DL n. 81/2008 respect to health protection and work safety [21].

\subsection{The USA experience}

Federal Management Emergency Agency (FEMA) is a part of DHS that supports citizens and first responders to ensure that as a nation that work together to build, 
sustain, and improve the capability to prepare for, protect against, respond to, recover from, and mitigate all hazards.

Figure 5 shows USA education, training and exercise activities.

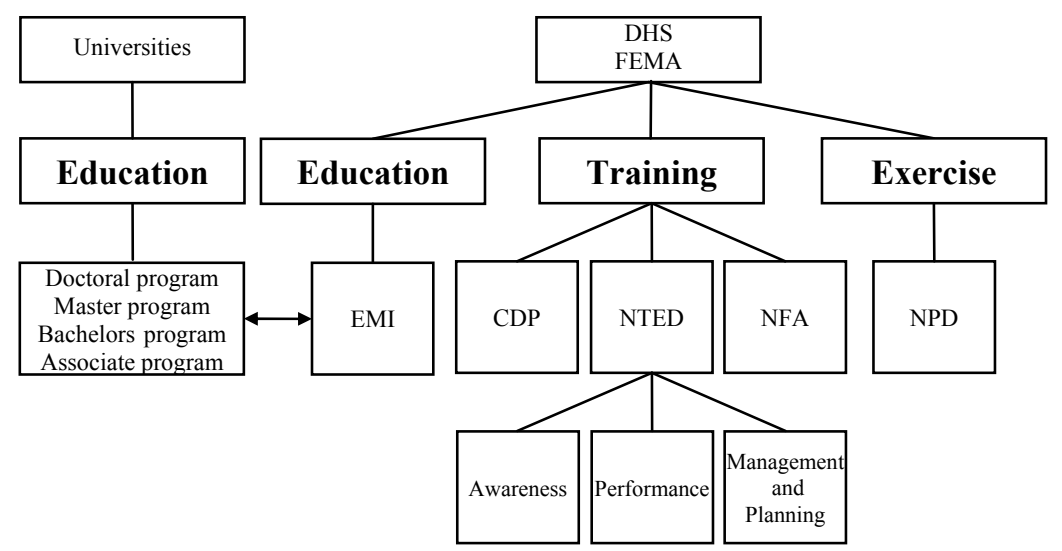

Figure 5: USA education, training and exercise scheme.

The FEMA approach [22-24] defines a continuous cycle process of five elements (Figure 6):

- planning is a process consisting of logical steps to identify a mission or requirement, develop, analyze, and compare alternate courses of action, select the best practice of action, and produce a plan [25];

- training and education is a process that considers training and education; the first concerns with teaching what to think and what the answers ought to be and the second concerns all about teaching how to think and what the questions ought to be [26];

- $\quad$ exercise is a process to train for, assess, practise and improve performance in prevention, protection. response and recovery capabilities in a risk-free environment [27]; exercises include discussion based exercises and operations based exercises (Figure 7);

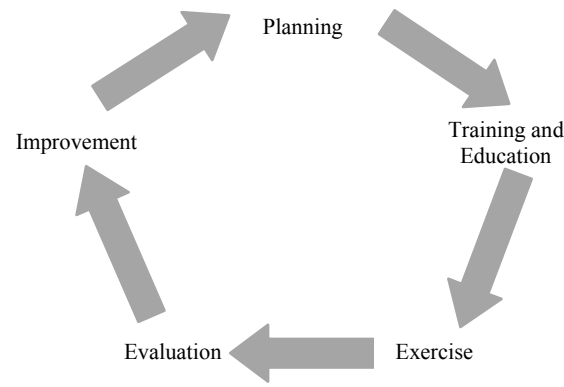

Figure 6: Cycle process emergency management. 
- $\quad$ evaluation is a process of examining, measuring and/or judging how well an entity, procedure, or action has met or is meeting stated objectives [28];

- improvement is a process by which the observations and recommendations recorded are resolved through development of corresctive actions [29].

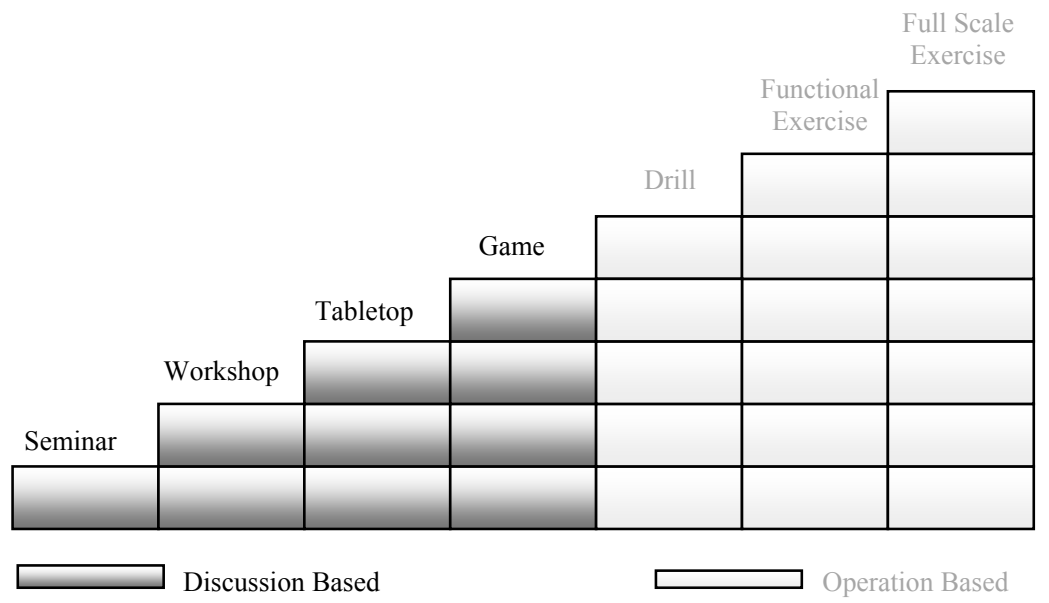

Figure 7: $\quad$ USA experience [24].

FEMA National Training Program offers training, education and exercises by four institutes: Center for Domestic Preparedness (CDP), Emergency Management Institute (EMI), National Training and Education Division (NTED) and National Fire Academy (NFA) [30]. Among these EMI established in 1994 Emergency Management Higher Education Program (EM Hi-Ed) to encourage and support the dissemination of hazard, disaster, and emergency managementrelated information in colleges and universities across the United States. This program aim to institute emergency management higher education by: doctoral programs; masters programs; bachelors programs; associate programs (community, technical and junior colleges) [31]. NTED offers three levels of courses [32]:

- $\quad$ awareness level courses are designed for responders who require the skills necessary to recognize and report a potential catastrophic incident or who are likely to witness or investigate an event involving the use of hazardous and/or explosive devices;

- performance level courses are designed for first responders who perform tasks during the initial response to a catastrophic event, such as safeguarding the at-risk public, rescuing victims, or decontaminating victims.

- management and planning level courses are designed for managers who build plans and coordinate the response to a mass consequence manmade or natural event. 
The FEMA also maintains the Homeland Security Exercise and Evaluation Program (HSEEP) by National Preparedness Directorate (NPD) [23]. HSEEP is a capabilities and performance-based exercise program that provides a standardized methodology and terminology for exercise design, development, conduct, evaluation, and improvement planning. It constitutes a national standard for all exercises (Figure 6). Through exercises, the National Exercise Program (NPE) [24] supports organizations to achieve objective assessments of their capabilities so that strengths and areas for improvement are identified, corrected, and shared as appropriate prior to a real incident.

\section{Prototypal training experience at LAST}

Training activities contribute to improve evacuation planning by means of an increase of capability.

In Italy, SICURO project has been organized by LAST - Laboratory for Transport System Analysis (Mediterranean University, Reggio Calabria). It comprises an extended experimentation phase of population evacuation from an urban area (Melito Porto Salvo, Italy), in order to construct a database which is required to specify and to calibrate a models system for transportation system analysis in urban area in emergency conditions and validate general procedure for risk reduction in term of exposure.

In the set of SICURO project activities, training and exercises have been realized. In particular, to test a local evacuation plan, a system of models, exercises and discussion-based training (seminars and workshops) have been implemented: system of models allow estimation of the evacuation times of an urban area; two exercises are carried out in the same town, to test and to monitor evacuation procedures of the town hall and school buildings (first exercises) and public buildings, private and commercial buildings in the same area (second exercises); before exercises implementation, two seminars with political and technical organs are organized; between the first and the second exercise, two workshops are realized to verify results of the first exercise; after exercises implementation, a two days discussion based course is realized that include a seminar about simulation models and planning (first day) and a workshop to apply and to test evacuation procedures (second day). In these training courses, a review of activities and results monitored in the exercises is presented. Among effects of training courses, a reduction of evacuation times (about 20\%) is obtained.

In the same project context, a set of tabletops, with annual frequency, are organized finalized to collect data in a stated preference survey.

In the SICURO project a possible indicator has been defined. The percentage of evacuation time $t_{e}$ respect to available period to evacuate $\Delta_{\mathrm{e}}=\left(\Delta_{1}+\Delta_{2}\right)$ is a metric to assess an exercise that contribute to improve evacuation planning capability in order to save lives.

The review of international experiences, in the knowledge of the authors, don't give specific metrics to evaluate preparedness measures, and don't report any indicators about the increasing of efficiency or the reduction of evacuation 
time. Further work is needed to analyze the relationship between training, and in the specific discussion - based, and evacuation outcomes, and in one word reduction of risk.

\section{References}

[1] Russo F. and Vitetta A., Risk evaluation in a transportation system. International Journal of Sustainable Development and Planning, 1 (2), pp. 170-191, 2006.

[2] Russo F. and Vitetta A., Safety of users in road evacuation: General methodology and main results. WIT Transactions on the Built Environment, Volume 96, Urban Transport XIII, Urban Transport and the Environment in the 21st century, pp. 763-772, 2007.

[3] Australia Governments, Emergency Management Approaches, http://www.ema.gov.au/ (last access January, 2011).

[4] USA, Department of Homeland Security Report to congress on catastrophic hurricane evacuation plan evaluation. www.fhwa.dot.gov/reports/ hurricanevacuation/ (last access January, 2011).

[5] European Commission, European civil protection, http:// ec.europa.eu/ echo/ civil_protection/ civil/ index.htm (last access January, 2011).

[6] Russo C. and Chilà, Domanda di trasporto in condizioni di emergenza. Modelli e metodi per la simulazione, applicazione ad un caso reale, Franco Angeli, Milano, 2007.

[7] Russo, F. and Rindone C., Planning in road evacuation: classification of exogenous activities. WIT Transactions on the Built Environment, Volume 116, Urban Transport XVII, Urban Transport and the Environment in $21^{\text {st }}$ Century, Pratelli \& Brebbia C. A. (ed.), WIT Press, Southampton, pp. 639$651,2011$.

[8] Vitetta A., Musolino G. and Marcianò F.A., Safety of users in road evacuation: Supply and demand-supply interaction models for users. WIT Transactions on the Built Environment, Volume 96, Urban Transport XIII, Urban Transport and the Environment in the 21st century, Brebbia C. A. (ed.), WIT Press, Southampton, pp. 783-792, 2007.

[9] Vitetta A., Musolino G. and Marcianò F. A., Safety of users in road evacuation: calibration of cost functions and simulation. WIT Transactions on the Built Environment, Volume 101, Urban Transport XIV, Urban Transport and the Environment in the 21st century, Brebbia C. A. (ed.), WIT Press, Southampton, pp. 715-725, 2008.

[10] Vitetta A., Musolino G. and Marcianò F.A., Safety of users in road evacuation: Modelling and DSS for transport supply and supply-demand interaction. WIT Transactions on Ecology and the Environment, Volume 120, Sustainable Development and Planning IV, vol.1, Brebbia C. A. (ed.), WIT Press, Southampton, pp. 475-484, 2009.

[11] Vitetta A., Quattrone A. and Polimeni A., Safety of users in road evacuation: design of path choice models for emergency vehicles. WIT Transactions on the Built Environment, Volume 96, Urban Transport XIII, 
Urban Transport and the Environment in the 21st century, Brebbia C. A. (ed.), WIT Press, Southampton, pp. 803-812, 2007.

[12] Vitetta A., Quattrone A. and Polimeni A., Safety of users in road evacuation: Modelling and DSS for paths design of emergency vehicles. WIT Transactions on Ecology and the Environment, Volume 120, Sustainable Development and Planning IV, vol.1, Brebbia C. A. (ed.), WIT Press, Southampton, pp. 485-495, 2009.

[13] Vitetta A., Quattrone A. and Polimeni A., Safety of users in road evacuation: algorithms for path design of emergency vehicles. WIT Transactions on the Built Environment, Volume 101, Urban Transport XIV, Urban Transport and the Environment in the 21st century, Brebbia C. A. (ed.), WIT Press, Southampton, pp. 727-737, 2008.

[14] Musolino G. and Vitetta A., Short-term forecasting in road evacuation: calibration of a travel time function. WIT Transactions on the Built Environment, Volume 116, Urban Transport XVII, Urban Transport and the Environment in $21^{\text {st }}$ Century, Pratelli \& Brebbia C. A. (ed.), WIT Press, Southampton, pp. 615-626, 2011.

[15] Polimeni A. and Vitetta A., Dynamic vehicle routing in road evacuation: a model for route design. WIT Transactions on the Built Environment, Volume 116, Urban Transport XVII, Urban Transport and the Environment in $21^{\text {st }}$ Century, Pratelli \& Brebbia C. A. (ed.), WIT Press, Southampton, pp. 627-638, 2011.

[16] Marcianò F.A., Musolino G. and Vitetta A., Within day traffic assignment and signal setting in road evacuation: a procedure with explicit path enumeration. WIT Transactions on the Built Environment, Volume 117, Safety and Security engineering IV, Guarascio M., Reiners G. Brebbia C. A. \& Garzia F. (ed.), WIT Press, Southampton, pp. 403-414, 2011.

[17] Polimeni A. and Vitetta A., Dynamic vehicle routing in road evacuation: route design experimentation. WIT Transactions on the Built Environment, Volume 117, Safety and Security engineering IV, Guarascio M., Reiners G. Brebbia C. A. \& Garzia F. (ed.), WIT Press, Southampton, pp. 391-402, 2011.

[18] EU, European Commission, European civil protection, http:// ec.europa.eu/ echo/files/media/publications/cp_training_brochure_2009_en.pdf, (last access January, 2011).

[19] EU, Bologna process, http:// www.bolognaprocess.it/ content/ index.php? action=read_cnt\&id_cnt=5718, (last access March, 2012).

[20] Italy, Ministero dell'Università e della Ricerca, Decreto ministeriale 270/2004,http://www.miur.it/Miur/UserFiles/Notizie/2007/DMCdL_magist rale.pdf, (last access March, 2012).

[21] Italy, Decreto legislativo 81/2008, http:// www.camera.it/ parlam/ leggi/ home.htm, (last access March, 2012).

[22] USA, Federal Emergency Management Agency, http:// www.fema.gov/ prepared/ train.shtm\#1, (last access January, 2011). 
[23] USA; Federal Emergency Management Agency, http:// www.fema.gov/ pdf/ emergency/ nrf/National_Preparedness_Guidelines.pdf, (last access January, 2011).

[24] USA, Department of Homeland Security, https:// hseep.dhs.gov/ pages/ 1001_HSEEP7.aspx, (last access January, 2011).

[25] USA, Federal Emergency Management Agency, Integrated planning System for homeland Security, 2008, http:// morsnet.pbworks.com/ f/MORS+Presentation+Martin+Sullivan.pdf, (last access February, 2012).

[26] Blanchard B. W., Guide to emergency management and related terms, definitions, concepts, acronyms, organizations, programs, guidance, executive orders \& legislation, http:// training.fema.gov/ EMIWeb/ edu/, (last access February, 2012).

[27] USA, Federal Emergency Management Agency, HSEEP glossary, https://hseep.dhs.gov/DHSResource/Glossary.aspx\#E， (last access last access February, 2012).

[28] USA, Department of Homeland Security, DHS risk lexicon, 2008, http://www.dhs.gov/xlibrary/assets/dhs_risk_lexicon.pdf, (last access February, 2012).

[29] USA, Department of Homeland Security, HSEEP vol.III, 2007, https://hseep.dhs.gov/support/VolumeIII.pdf, (last access February, 2012).

[30] USA, Federal Emergency Management Agency, http://training.fema.gov/, (last access February, 2012).

[31] USA, Federal Emergency Management Agency, FEMA emergency management higher education program description, http:// training.fema.gov/ EMIWeb/edu, (last access February, 2012).

[32] USA, National Training and Education Division https:// www.firstrespondertraining.gov/catalogs/NTED Course Catalog.pdf, (last access February, 2012). 